University of Montana

ScholarWorks at University of Montana

Numerical Terradynamic Simulation Group

Publications

Numerical Terradynamic Simulation Group

3-2007

\title{
Evaluating water stress controls on primary production in biogeochemical and remote sensing based models
}

Qiaozhen Mu

Maosheng Zhao

Faith Ann Heinsch

Mingliang Liu

Hanqin Tian

Auburn University Main Campus

See next page for additional authors

Follow this and additional works at: https://scholarworks.umt.edu/ntsg_pubs Let us know how access to this document benefits you.

\section{Recommended Citation}

Mu, Q., M. Zhao, F. A. Heinsch, M. Liu, H. Tian, and S. W. Running (2007), Evaluating water stress controls on primary production in biogeochemical and remote sensing based models, J. Geophys. Res., 112, G01012, doi:10.1029/2006JG000179

This Article is brought to you for free and open access by the Numerical Terradynamic Simulation Group at ScholarWorks at University of Montana. It has been accepted for inclusion in Numerical Terradynamic Simulation Group Publications by an authorized administrator of ScholarWorks at University of Montana. For more information, please contact scholarworks@mso.umt.edu. 
Authors

Qiaozhen Mu, Maosheng Zhao, Faith Ann Heinsch, Mingliang Liu, Hanqin Tian, and Steven W. Running 


\title{
Evaluating water stress controls on primary production in biogeochemical and remote sensing based models
}

\author{
Qiaozhen Mu, ${ }^{1}$ Maosheng Zhao, ${ }^{1}$ Faith Ann Heinsch, ${ }^{1}$ Mingliang Liu, ${ }^{2}$ Hanqin Tian, ${ }^{2}$ \\ and Steven W. Running ${ }^{1}$ \\ Received 9 February 2006; revised 8 September 2006; accepted 6 October 2006; published 8 February 2007.
}

[1] Water stress is one of the most important limiting factors controlling terrestrial primary production, and the performance of a primary production model is largely determined by its capacity to capture environmental water stress. The algorithm that generates the global near-real-time MODIS GPP/NPP products (MOD17) uses VPD (vapor pressure deficit) alone to estimate the environmental water stress. This paper compares the water stress calculation in the MOD17 algorithm with results simulated using a process-based biogeochemical model (Biome-BGC) to evaluate the performance of the water stress determined using the MOD17 algorithm. The investigation study areas include China and the conterminous United States because of the availability of daily meteorological observation data. Our study shows that VPD alone can capture interannual variability of the full water stress nearly over all the study areas. In wet regions, where annual precipitation is greater than $400 \mathrm{~mm} / \mathrm{yr}$, the VPD-based water stress estimate in MOD17 is adequate to explain the magnitude and variability of water stress determined from atmospheric VPD and soil water in Biome-BGC. In some dry regions, where soil water is severely limiting, MOD17 underestimates water stress, overestimates GPP, and fails to capture the intraannual variability of water stress. The MOD17 algorithm should add soil water stress to its calculations in these dry regions, thereby improving GPP estimates. Interannual variability in water stress is simpler to capture than the seasonality, but it is more difficult to capture this interannual variability in GPP. The MOD17 algorithm captures interannual and intraannual variability of both the Biome-BGCcalculated water stress and GPP better in the conterminous United States than in the strongly monsoon-controlled China.

Citation: Mu, Q., M. Zhao, F. A. Heinsch, M. Liu, H. Tian, and S. W. Running (2007), Evaluating water stress controls on primary production in biogeochemical and remote sensing based models, J. Geophys. Res., 112, G01012, doi:10.1029/2006JG000179.

\section{Introduction}

[2] Water availability is the primary limiting factor for vegetation growth over $40 \%$ of the Earth's vegetated surface, while an additional $33 \%$ is limited by cold temperatures and frozen water, rurther limiting water availability for plant growth [Nemani et al., 2003]. Vegetation responds to water deficits in several ways [Waring and Running, 1998]. Even mild soil water deficits begin to inhibit cellular expansion, xylem water fiow from roots to leaves, and phloem sugar transfer in the stems of growing plants. Lack of mobile water has similar impacts on reducing plant leaf area, transpiration, growth, and related ecosystem activity [Kunning and Kimball, 2005].

\footnotetext{
${ }^{1}$ Numerical Terradynamic Simulation Group, Department of Ecosystem and Conservation Sciences, University of Montana, Missoula, Montana, USA.

${ }^{2}$ School of Forestry and Wildlife Sciences, Auburn University, Auburn, Alabama, USA.

Copyright 2007 by the American Geophysical Union. 0148-0227/07/2006JG000179\$09.00
}

[3] Terrestrial net primary production (NPP), equal to the difference between gross primary production (GPP) and autotrophic respiration $(\mathrm{Ra})$, plays an important role in the carbon balance of the biosphere. NPP is receiving increased attention not only because it is related to the global carbon cycle, but also because it is greatly influenced by the associated effects of changing climate on the carbon cycle [Prentice et al., 2001]. Photosynthesis is the only process by which to assimilate $\mathrm{CO}_{2}$ from the atmosphere into terrestrial primary production, and stomata are the major pathways for transfer of trace gases between vegetation and the atmosphere. The stomatal conductance and photosynthetic assimilation rate are largely controlled by environmental factors such as irradiance, temperature, water availability, and nutrition [Wong et al., 1985a, 1985b, 1985c; Lange et al., 1987]. Therefore global terrestrial primary production models incorporate these environmental factors to study the terrestrial carbon balance and vegetation dynamics under a changing climate [Cramer et al., 1999; Arora, 2002]. Plant water deficits induce progressive leaf stomatal closure, reducing plant water loss via transpiration while also slow- 
ing photosynthesis and canopy-atmosphere gas exchange. Sustained drought will produce early leaf senescence and shedding and may impact ecosystem leaf area for a number of years [Running and Kimball, 2005]. During most of the growing season, when light and temperature are great enough to maximize stomatal conductance, water limitation is the dominant climatic controller of stomatal conductance. There are different approaches to introducing water limitations on primary production in different models, and for most process-based ecosystem models, water limitations are calculated for both the soil and the air [Churkina et al., 1999].

[4] The Biome-BGC ecosystem model is a processbased biogeochemical model, simulating ecosystem cycles of carbon, water and nitrogen at regional and global scales [Running and Hunt, 1993; White et al., 2000; Thornton et al., 2002]. The water stress calculation in Biome-BGC is determined by the combined stresses from soil-leaf water potential (PSI) and the atmospheric water vapor pressure deficit (VPD; details in section 2.1). The operational MODIS (Moderate Resolution Imaging Spectroradiometer) Production Efficiency Model (MOD17) on the Terra satellite is used to generate 8-day near-real-time vegetation primary production [Zhao et al., 2005] (also F. A. Heinsch et al., User's Guide GPP and NPP (MOD17A2/A3) Products NASA MODIS Land Algorithm, 2003, available at http://www.ntsg.umt.edu/modis/MOD17UsersGuide.pdf). MOD17 is based on the radiation use efficiency logic suggested by Monteith [Monteith, 1972, 1977; Running et al., 2000, 2004], and the model is similar to existing production efficiency models [Prince and Goward, 1995; Potter et al., 1993; Ruimy et al., 1994; Field et al., 1995]. One key difference between MOD17 and Biome-BGC is the implementation of water stress control through VPD (MOD17) instead of soil moisture (Biome-BGC; details in section 2.2). Although there are justifications for using only VPD in calculating MOD17, and the MODIS GPP has been validated at the site level using a number of eddy covariance flux tower measurements across different climatic regimes and biome types [Turner et al., 2003, 2005, 2006; Heinsch et al., 2006], there is little known about the capability of MOD17 to capture interannual and intraannual water stress variability on GPP at the regional level. Previous studies have demonstrated that Biome-BGC can accurately simulate vegetation production [Kimball et al., 1997b, 1997c; Thornton et al., 2002]. The purpose of this paper is to compare the results from MOD17 with those simulated by Biome-BGC to (1) evaluate if the MOD17 algorithm can express the water stress coming from both atmospheric VPD and soil water, and (2) ascertain if regional MOD17 GPP estimates are reasonable.

[5] Both models require daily gridded meteorology data, however, daily observation stations in most areas of the globe are very sparse, especially in the tropics. In addition, existing global gridded climate data sets interpolated from observations such as the Climatic Research Unit data set (CRU at the University of East Anglia) [New et al., 2000] are monthly and not daily. The meteorology reanalysis data sets, such as ECMWF (European Centre for Medium-Range
Weather Forecasts) and NCEP/NCAR (National Centers for Environmental Prediction/National Center for Atmospheric Research) reanalysis data, are not accurate enough to be used to drive ecosystem models [Zhao et al., 2006], particularly for precipitation [Janowiak et al., 1998]. As a result, we have confined our study regions to China and the conterminous United States because of the availability of relatively long-term daily observed surface meteorological data sets required by both models. China and the United States are the third and fourth largest countries in area in the world, respectively, and both countries have diverse climatic regions and biome types [Hou, 1980; Chabot and Mooney, 1985].

[6] China and the conterminous United States cover most of the major climate types classified by Koeppe and De Long [1958], and both countries contain all the biome types listed in the recent MODIS UMD (University of Maryland) global land cover analysis [Friedl et al., 2002]. The dominant limiting factor for most parts of the two countries is water availability [Nemani et al., 2003]. The water-limited areas of Europe, for example, are mostly controlled by a Mediterranean climate, similar to parts of the western United States. For these reasons, results from the two countries should be applicable to most other vegetated areas on earth.

\section{Water Limitations on GPP in Biome-BGC and MOD17}

[7] Water stress for vegetation comes from both the soil and the atmosphere. In the MOD17 algorithm, VPD is the only variable directly related to environmental water stress, while both VPD and soil moisture are used for water stress calculations in Biome-BGC. The following subsections describe them in detail.

\subsection{Biome-BGC}

[8] Biome-BGC (version 4.1.2) uses the canopy photosynthesis model proposed by De Pury and Farquhar [1997]. The model uses a single layer sun/shade model, separately integrating the sunlit and shaded leaf fractions of the canopy, which is as accurate as and simpler than many multilayer models [Sinclair et al., 1976; Sellers et al., 1992; Wang and Jarvis, 1993; Leuning et al., 1995]. Leaf stomatal conductance in the model is controlled in part by water availability.

[9] The effect of water stress on leaf stomatal conductance in Biome-BGC is a combination of the stresses from both soil-leaf water potential (PSI) and atmospheric water vapor pressure deficit (VPD) [Rastetter et al., 1992; Cosby and Hornberger, 1984; Landsberg, 1986; Körner, 1995]. When PSI is lower than a given threshold PSI (PSI close) or VPD is higher than the VPD threshold (VPD_close), water stress will cause stomata to close completely, halting photosynthesis. On the other hand, when PSI is higher than PSI_open, and VPD is lower than VPD_open, there will be no water stress on the vegetation. With other conditions (e.g., air temperature, light) being optimal, the stomata will open fully, leading to a maximum rate of photosynthesis. In the Biome-BGC model, the VPD multiplier (MVPD) is 
expressed in equation (1) and the PSI multiplier (MPSI) is in (2).

$$
\text { MVPD }=\left\{\begin{array}{l}
1.0 \\
\frac{\text { VPD_close }- \text { VPD }}{\text { VPD_close }- \text { VPD_open }} \\
0.0
\end{array}\right.
$$$$
\text { VPD_open } \leq \text { VPD } \leq \text { VPD_close }
$$

$$
\text { MPSI }=\left\{\begin{array}{l}
1.0 \\
\frac{\text { PSI_close }- \text { PSI }}{\text { PSI_close }- \text { PSI_open }} \\
0.0
\end{array}\right.
$$

The final water stress scalar in Biome-BGC is expressed as MVPD*MPSI (VPD/SM).

\subsection{MOD17 Algorithms}

[10] For MOD17 Collection 4.5, VPD is the only variable directly related to environmental water stress. The MODIS GPP is calculated as

$G P P=\varepsilon_{\max } \times m\left(T_{\min }\right) \times m(V P D) \times F P A R \times S W r a d \times 0.45$,

where $\varepsilon_{\max }$ is the maximum light use efficiency, the multipliers $m\left(T\right.$ min) and $m(V P D)$ reduce $\varepsilon_{\max }$ under unfavorable conditions of low temperature and high VPD, respectively. FPAR is the fraction of absorbed Photosynthetically Active Radiation, and SWrad is incoming shortwave solar radiation. In this study, we concentrate on $m(V P D)$ (VPD_only). VPD_only for MOD17 is calculated using the same formula as Biome-BGC (equation (1)), except that VPD_open and VPD_close have different threshold values for different biome types than those in Biome-BGC.

[11] There are several practical and theoretical reasons for using only VPD to represent environmental water stresses in MOD17. Realistically, MODIS GPP is a near-real-time global data set produced at a $1-\mathrm{km}$ resolution and an 8 -day interval. Owing to the unavailability of gridded global surface observations in near-real-time, the input meteorology data are obtained from global climate models (reanalysis). Precipitation results from reanalysis data sets are highly model-dependent and more problematic than temperature estimates [Janowiak et al., 1998], and they are not accurate enough for driving ecosystem models. Additionally, biases exist by using different methods to calculate evapotranspiration (ET [Vorösmarty et al., 1998]), and hence calculated soil water will contain large uncertainties since soil water is determined by precipitation minus both ET and runoff. Furthermore, the calculation of soil water would tremendously increase the computational expense resulting from the increased number of inputs and modules required for calculating the water balance for each vegetated MODIS pixel. Theoretically, some studies have suggested that atmospheric conditions reflect surface parameters [Bouchet, 1963; Morton, 1983], and VPD can be used as an indicator$$
\text { VPD }<\text { VPD_open }
$$$$
\text { VPD }>\text { VPD_close }
$$

of environment water stress [Running and Nemani, 1988; Granger and Gray, 1989]. Nemani et al. [2002, auxiliary

VPD $<$ VPD_open
VPD_open $\leq$ VPD $\leq$ VPD_close
VPD $>$ VPD_close

PSI > PSI_open

PSI_open $\geq$ PSI $\geq$ PSI_close

PSI $<$ PSI_close

material] found that, for 1900-1993 in the conterminous United States, ET and runoff were positively correlated with precipitation, and, furthermore, that VPD was negatively correlated with precipitation. As a result, VPD was negatively and significantly related to soil water. There is also substantial evidence suggesting that stomatal conductance and photosynthesis are sensitive to variations in VPD [Kawamitsu et al., 1993; Marsden et al., 1996; Dang et al., 1997; Oren et al., 1999; Misson et al., 2004]. Additionally, NDVI, calculated from satellite observations, has been found to be related to water availability, especially for water limited regions [Paruelo and Lauenroth, 1995; Schultz and Halpert, 1995; Douglas and Prince, 1996; Nicholson et al., 1998]. FPAR is linearly related to NDVI [Kumar and Monteith, 1982; Asrar et al., 1984; Sellers, 1987], and leaf area index (LAI) is also strongly related to NDVI [ Nemani et al., 1996], suggesting that the status of satellite-derived LAI and FPAR indirectly reflects the water status of both the soil and atmosphere. As a result, it is feasible to use VPD and other water stress information provided by satellite-derived FPAR in the MOD17 algorithm to represent environment water stress.

\section{Data and Methods}

[12] The MOD17 algorithm requires vegetation data, satellite LAI and FPAR data, daily temperature, VPD, and solar radiation as model inputs for calculating primary production. However, unlike the MOD17 algorithm, Biome-BGC is a process-based model, which does not use remotely sensed data such as LAI and FPAR as inputs. Instead, it dynamically simulates LAI and other carbon and water cycle components in ecosystems. Biome-BGC requires prescribed vegetation and site conditions, meteorology, and vegetation-specific parameter values to simulate daily fluxes and states of energy, carbon, water, and nitrogen for the vegetation and soil components of terrestrial ecosystems [Thornton et al., 2002].

\subsection{Daily Gridded Meteorology Data}

[13] Daily meteorology data for both countries, including daily precipitation, solar radiation, vapor pressure deficit (VPD), temperature, and day length, were generated using 

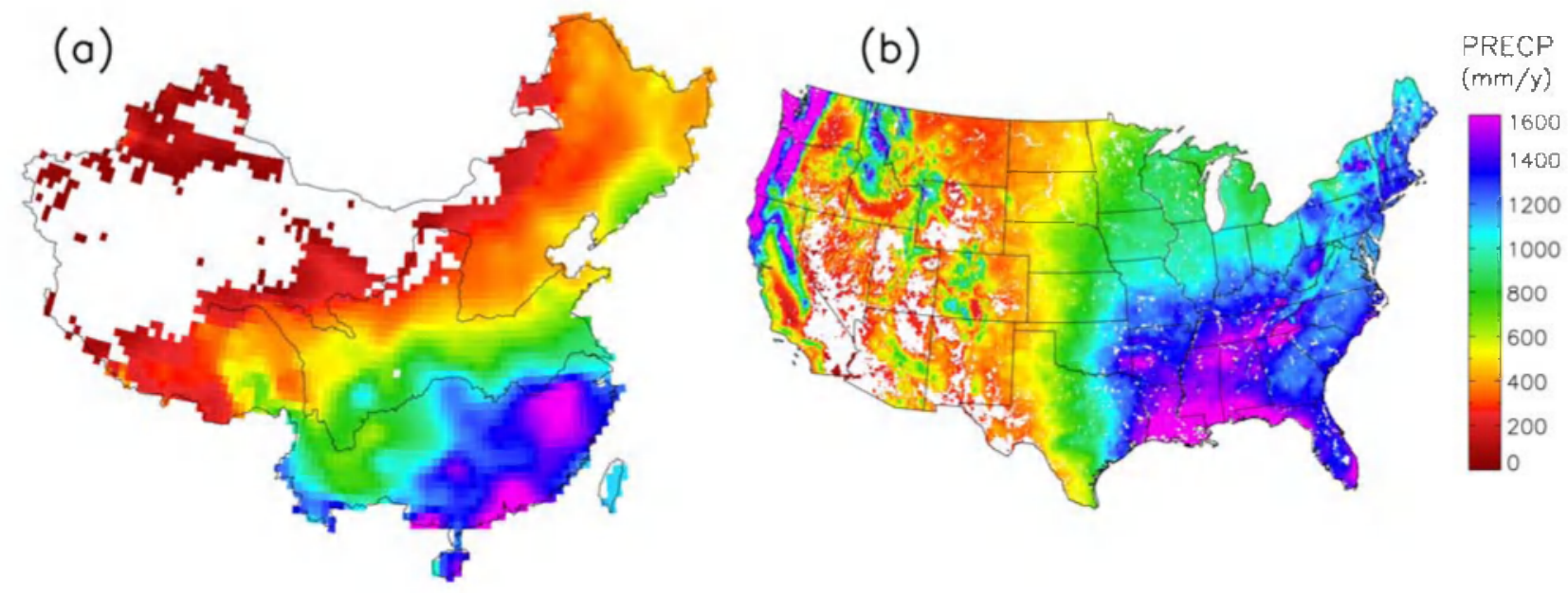

Figure 1. The mean average annual total precipitation $(\mathrm{mm} / \mathrm{yr})$ in (a) China averaged over $1982-2000$ and (b) the conterminous United States averaged over 1982-1997. Vegetated regions are shown in color, and the regions in white are nonvegetated areas, including water bodies, barren land and built-up areas.

the DAYMET algorithm [Thornton and Running, 1999; Kimball et al., 1997a; Thornton et al., 1997] based on available surface weather station observations. In China, the resolution is $0.5^{\circ}$ latitude/longitude, spanning 1961-2000. The daily gridded 1-km DAYMET data for the conterminous United States are available for 1980-1997 (http:// www.daymet.org/).

\subsection{Satellite Data}

[14] The FPAR and LAI data set derived from AVHRR (Advanced Very High Resolution Radiometer) spans the period 1982-2000 [Myneni et al., 1997; Nemani et al., 2003]. Considering this and the availability of the meteorology data, the study period is $1982-1997$ for the conterminous United States in this paper and 1982-2000 for China. Available monthly AVHRR FPAR and LAI are at an $8-\mathrm{km}$ resolution for the conterminous United States, so the $1-\mathrm{km}$ meteorology data were aggregated to $8-\mathrm{km}$ for the conterminous United States. In China, the resolution of AVHRR data is $0.5^{\circ}$, matching the resolution of the meteorological data.

\subsection{Additional Ancillary Data Sets}

[15] In China, both models use the aggregated $0.5^{\circ}$ land cover classifications developed by De Fries et al. [1998]; in the conterminous United States, the dominant vegetation data for each $8-\mathrm{km}$ pixel is aggregated from the latest $1-\mathrm{km}$ MODIS Collection 4 land cover data [Friedl et al., 2002]. For Biome-BGC simulations over China, mixed forest is treated as deciduous needle-leaf forest (DNF); woodland as shrub; and crops and barren areas as grass. In the conterminous United States, crops, urban areas, snow and ice, and barren pixels are treated as grass in Biome-BGC. Since crops are treated as grass, irrigation, fertilization and pesticide effects are ignored.

[16] In China, soil texture (percent sand/silt/clay) and soil depth data for Biome-BGC inputs are derived from the second soil inventory data [Zhang et al., 2005; Wang et al., 2003]; in the conterminous United States, 8-km soil data are aggregated from the State Soil Geographic (STATSGO) data set compiled by the Natural Resources Conservation Service (NRCS; http://www.ofps.ucar.edu/gcip/soils.html). In China, the $0.5^{\circ}$ elevation data input for Biome-BGC is integrated from the China national DEM (digital elevation model) data provided by The Data Center for Resources and Environmental Sciences (RESDC, Chinese Academy of Sciences); while in the conterminous United States, elevation data are $8-\mathrm{km}$ data aggregated from GTOPO30, a global DEM created by the U.S. Geological Survey (USGS, http://edcdaac.usgs.gov/gtopo30/gtopo30.asp).

\section{Results and Analyses}

\subsection{Water Stress Scalars}

[17] The temperature-defined growing season typically starts in April and lasts until October, with most photosynthesis occurring during this period. Therefore, to analyze the intraannual and interannual variability of water stress and its effects on GPP, we define the growing season as the period from April to October. The annual and monthly results presented in this paper are the results for the growing seasons only unless otherwise specified.

\subsubsection{Spatial Patterns of Water Stress Scalars and GPP}

[18] The change in soil water equals precipitation minus both ET and runoff. Precipitation is the source of environmental water, and as expected, it is the dominant climatic factor responsible for terrestrial primary production in China [Zhao et al., 2001; Cao et al., 2003; Tao et al., 2003]. Increased precipitation and humidity also contributed the most to the conterminous United States carbon cycle during 1990-1993 [Nemani et al., 2002]. When there is plenty of free soil water available, trees and grasses will develop large leaf areas and transpire at higher rates [Landsberg, 1999; Myers et al., 1996; Cromer et al., 1993]. In light of this information, the spatial patterns of observed precipitation and the Biome-BGC-simulated ET are useful for understanding water stress conditions.

[19] The mean average annual total precipitation is shown in Figure 1 (China: 1982-2000, the conterminous United States: 

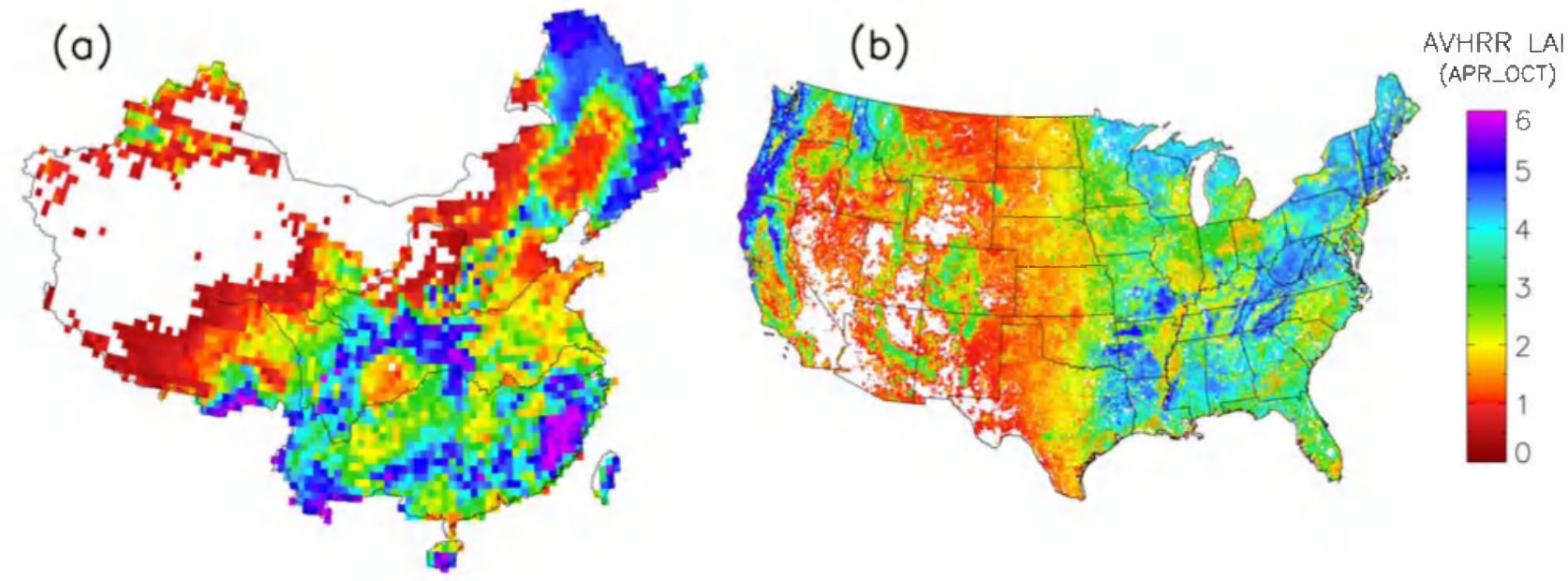

Figure 2. Annual AVHRR LAI averaged over growing season (April through October) in (a) China $(1982-2000)$ and (b) the conterminous United States (1982-1997). Vegetated regions are shown in color, and the regions in white are nonvegetated areas.

1982-1997). In China, the highest precipitation ( $>1000 \mathrm{~mm} / \mathrm{yr}$ ) occurs south to the downstream Yangtze River. The region between the Yangtze River and the Yellow River, the ChangBai-Mountain and the Xing-An-Ling areas have the second highest precipitation $(<1000 \mathrm{~mm} / \mathrm{yr}$, but $>400 \mathrm{~mm} / \mathrm{yr})$, while the lowest precipitation $(<400 \mathrm{~mm} / \mathrm{yr})$ occurs in west China and on the northeast China plain (Figure 1a). In the conterminous United States, the precipitation is higher in the east than in the west, with the notable exception of some parts of the northwest. Most of the western United States, where the land is predominately covered with grasses and shrubs, has less than $400 \mathrm{~mm} / \mathrm{yr}$ of precipitation (Figure 1b). The spatial ET during the growing season has a similar pattern to annual total precipitation for both countries, where areas of low precipitation have low ET and vice versa (not shown).

[20] While on a relatively short timescale (e.g., weekly or monthly), remotely sensed LAI (strongly related to NDVI) cannot reveal reduced photosynthesis resulting from water stress [Running and Nemani, 1988], the averaged growing season remotely sensed LAI over 16 or more years can reflect the real conditions of the vegetation growth and water availability [Goward et al., 1985; Running and Nemani, 1988], especially for water limited regions as discussed in the introduction (Figure 2). Generally, forests have higher LAI than shrubs, grasses, and crops. For the same biome type, AVHRR LAI is usually higher in wet than in dry areas. Where LAI is high, there should be plenty of available soil water, water stress should be low, and plants should be productive. For example, for the grasslands and crops in western China, the northeast China plain, the Shandong peninsula, and the middle/western United States, AVHRR LAI is lower than in other relatively wet crops and grasslands. The water stress from both the atmosphere and the soil should be strong, and primary production should be small. AVHRR LAI reflects the same water stress information as precipitation. For each biome type, then, the remotely sensed GPP in dry areas should be lower than that in wet areas.

[21] The annual and multiyear averaged monthly VPD/ SM and VPD_only are shown in Figure 3. For most parts of both countries, the effect of VPD_only is higher than VPD/ SM especially in west China, on the northeast China plain, along the southern to central Yangtze River, and in the middle/western United States, where the primary land cover types are grasses, crops, and shrubs. Biome-BGC calculates the potential soil water stress without considering the impacts of human activities on the water cycle (e.g., irrigation, drainage). Satellite-derived LAI and FPAR, however, can largely reveal the real water stress resulting not only from the effects of VPD and precipitation, but also from human influences. The combination of FPAR with VPD only (Figures 3e and 3f) should be able to indirectly incorporate both soil water and human influence information, as revealed in its similarity of AVHRR LAI (Figure 2). In both countries, the water stress scalar VPD_only is higher than VPD/SM almost everywhere, particularly in very dry areas such as west China. There is virtually no water limitation effect on the MOD17 algorithm, indicating that VPD only alone is insufficient. However, when VPD only is combined with FPAR and the results are compared with VPD/SM, the spatial patterns are similar, indicating that the combination of the two MODIS variables improves the water stress estimation of dry regions (Figures $3 \mathrm{e}$ and $3 \mathrm{f}$ ). As expected, the combination of VPD_only and FPAR is higher for wet regions than for dry areas, but the differences between these wet regions and some of the dry regions are not as great as they are for AVHRR LAI. VPD/SM is higher than the VPD_only/FPAR combination for most parts of China and the conterminous United States, but it is still lower in west China, the northeast China plain, and the western United States (Figures $3 \mathrm{a}$ and $3 \mathrm{c}$ and Figures $3 \mathrm{e}$ and $3 \mathrm{f}$ ). For semihumid agricultural regions such as the Shandong peninsula and the central United States, where the LAI is lower than LAI in other wet crop areas (Figure 2), the combination of VPD_only and FPAR has a similar magnitude to that of VPD/SM (Figures $3 e$ and 3f). This means that the combination of VPD_only and FPAR still underestimates the water stress in some dry regions, and soil water stress should be considered to improve GPP estimates. To verify 

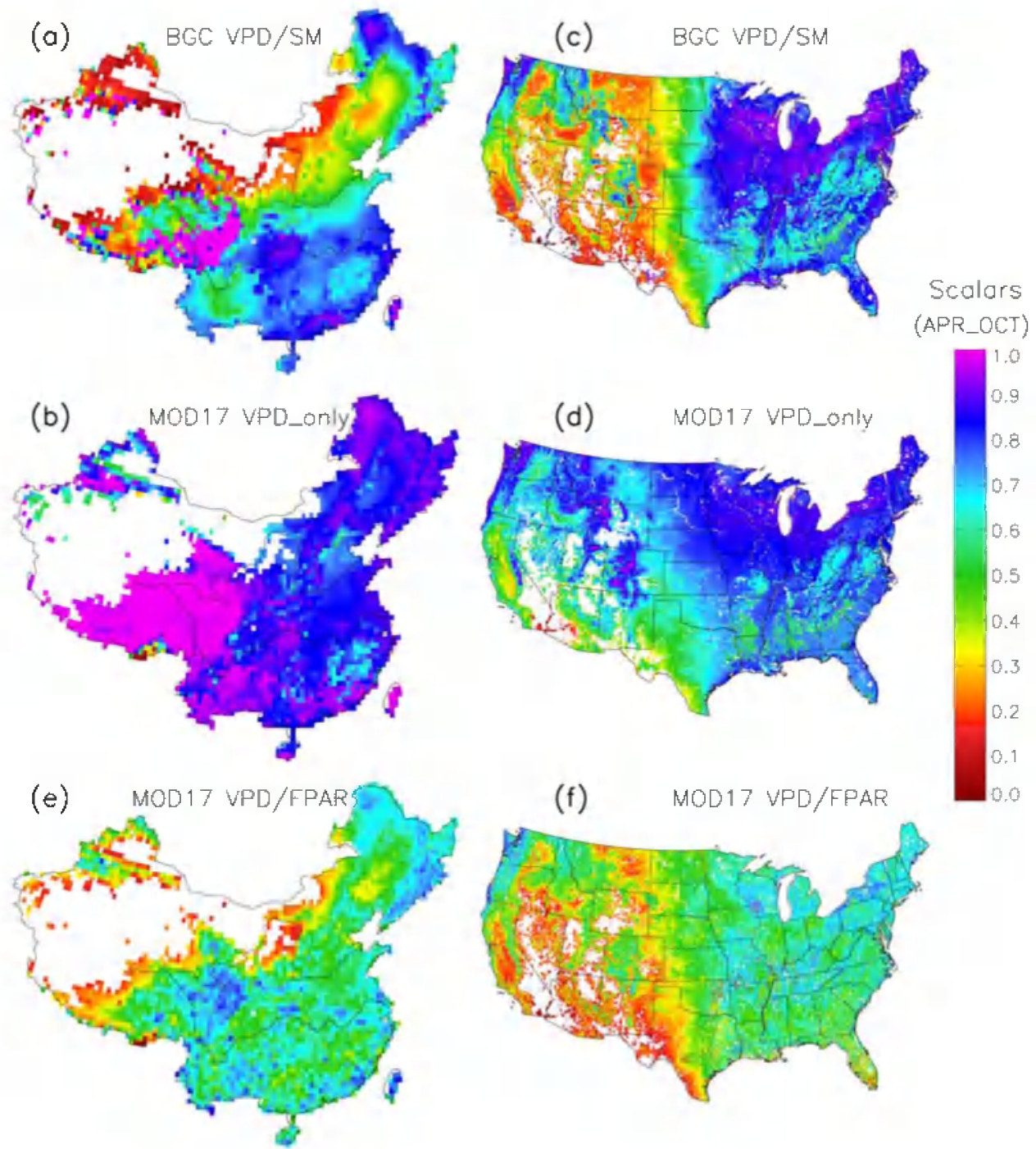

Figure 3. Annual water stress scalars averaged over growing season. (a) Biome-BGC water stress scalars (VPD/SM) and (b) MOD17 water stress scalars (VPD_only) in China; (c) VPD/SM and (d) VPD_only in the conterminous United States; MOD17 VPD_only*FPAR in (e) China and (f) the conterminous United States. Vegetated regions are shown in color, and the regions in white are nonvegetated areas.

this conclusion, the spatial MOD17 GPP mean is examined for the two countries below.

[22] In both China and the conterminous United States, the overall spatial patterns of MOD17 GPP are reasonable, with higher values for forests and shrubs, and lower values for grasses and crops (Figure 4). In addition, the general spatial pattern of MOD17 GPP is very similar to that of AVHRR LAI. For the agricultural areas around the Shandong peninsula and in the central United States, GPP is expected to be low where LAI is low (Figure 2). However, MOD17 GPP is just as high for these regions as for the regions of high LAI with the same land cover, suggesting that GPP is overestimated by the MOD17 algorithm in these regions. Recent validation activities by Leuning et al. [2005] for two Australian flux towers (tropical savanna and temperate forest) have shown similar results. They found that MOD17 overestimated GPP at the savanna site during the dry season but gave satisfactory estimates during the two wet seasons. They improved GPP predictions significantly for the savanna by modifying the MOD17 algorithm to account for rainfall and potential evaporation, a surrogate for soil water availability.

[23] These results suggest that the combination of VPD_only and FPAR in MOD17 still underestimates the water stress in some water limited areas, and this underestimated water stress leads to overestimation of GPP in these dry regions. They confirm that soil moisture should somehow be incorporated into the MOD17 algorithm, particularly in dry regions, to improve GPP estimates.

\subsubsection{Intraannual and Interannual Variations}

[24] To explore if the MOD17 algorithm can capture the intraannual and interannual variability of water stress simulated by Biome-BGC from both atmospheric VPD and soil water, the spatial correlation between annual and monthly VPD/SM and VPD_only is calculated during the growing 

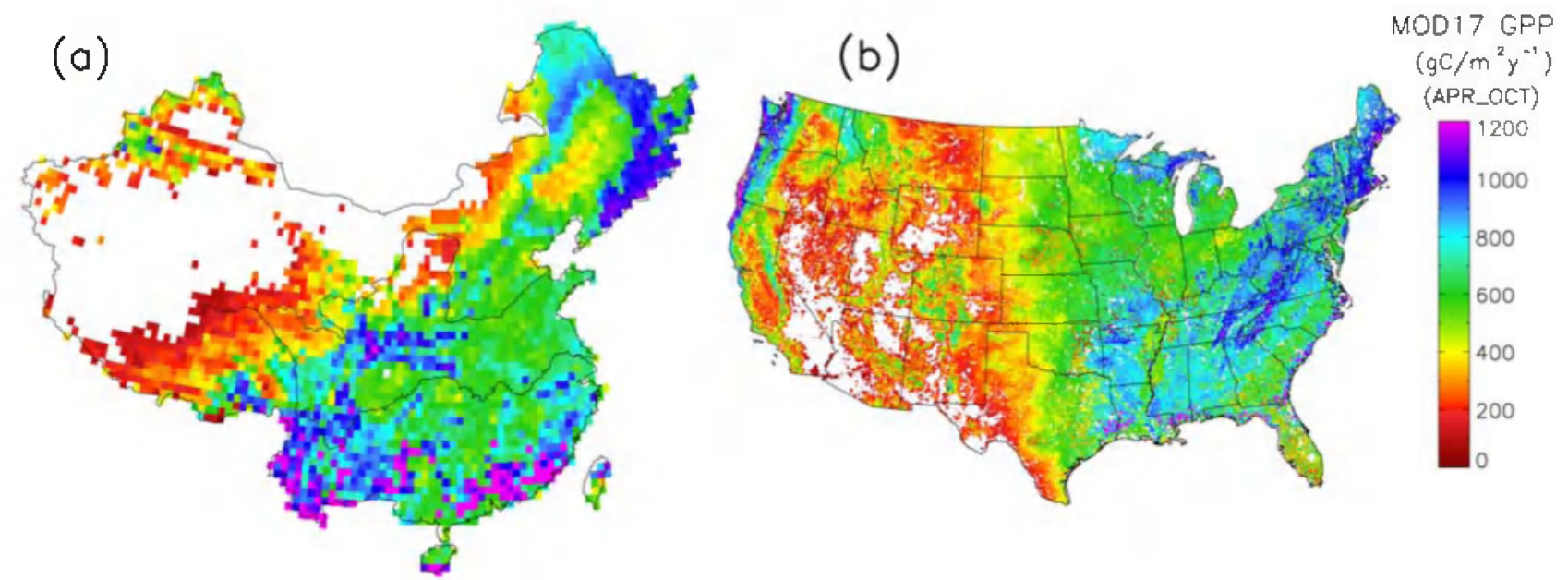

Figure 4. Annual MOD17 GPP summed over growing season in (a) China (1982-2000) and (b) the conterminous United States (1982-1997). Vegetated regions are shown in color, and the regions in white are nonvegetated areas.

season in China and the conterminous United States, respectively. FPAR is not used for this analysis because it is affected not only by the water stress but also by other variables such as solar radiation, temperature, nutrient availability, and human activity. In the annual analysis, the threshold correlation coefficients (r) for China (19 years) are $0.39(p<0.1)$ and $0.46(p<0.05)$. For the conterminous United States (16 years), threshold correlation coefficients are $0.43(p=0.1)$ and $0.50(p=0.05)$. Since there are only seven samples in the monthly correlation analysis during the growing season, we were unable to test for significance. The correlations are shown both by biome and spatially. For the different biome types, the monthly and annual correlation between VPD/SM and VPD_only is spatially aggregated on the basis of biome type. Since there is only one pixel for DNF in the conterminous United States, we ignore it in further analysis.

\subsubsection{Interannual Variations}

[25] The spatial correlation significance between annual VPD/SM and annual VPD_only is shown for China (Figure 5a) and the conterminous United States (Figure 5b). These two variables are significantly and positively correlated for most of the conterminous United States $(p<0.1)$. In China, although the correlation for most of the pixels passes the $p<0.1$ significance test, the correlation is negative for a few pixels in western China and insignificant for some pixels in western China, the Pearl Delta, and the Xiao-Xing-An-Ling area. Such negative or insignificant correlation might be caused by the following: (1) VPD_only cannot capture the interannual variability of the environmental water stress expressed by Biome-BGC VPD/SM and (2) there are no weather stations available from Taiwan and only a limited number in Xiao-Xing-An-Ling and western China, especially on the Tibetan Plateau, in Xinjiang and in

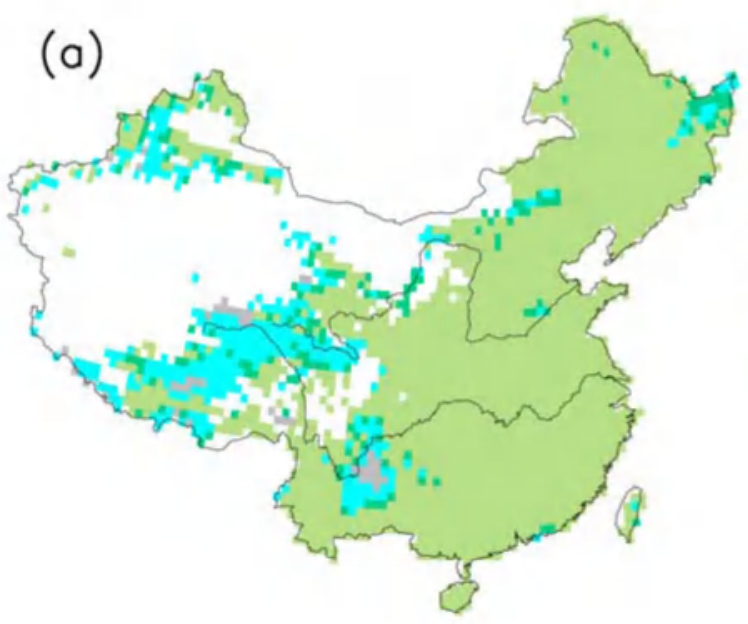

(b)

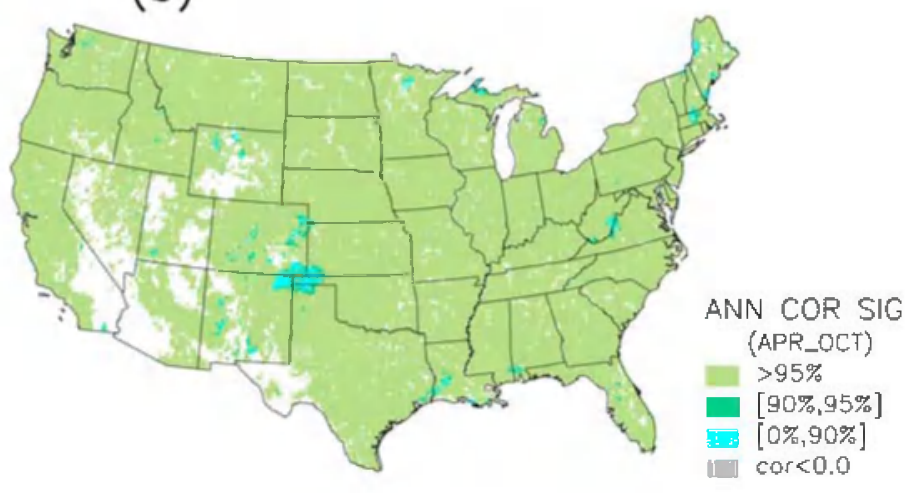

Figure 5. Spatial correlation significance between annual Biome-BGC water stress scalars (VPD/SM) and MOD17 water stress scalars (VPD_only) in (a) China (1982-2000) and (b) the conterminous United States (1982-1997). Vegetated regions are shown in color, and the regions in white are either nonvegetated areas, or the areas where the standard deviation of annual water stress scalars is less than $10^{-5}$. 

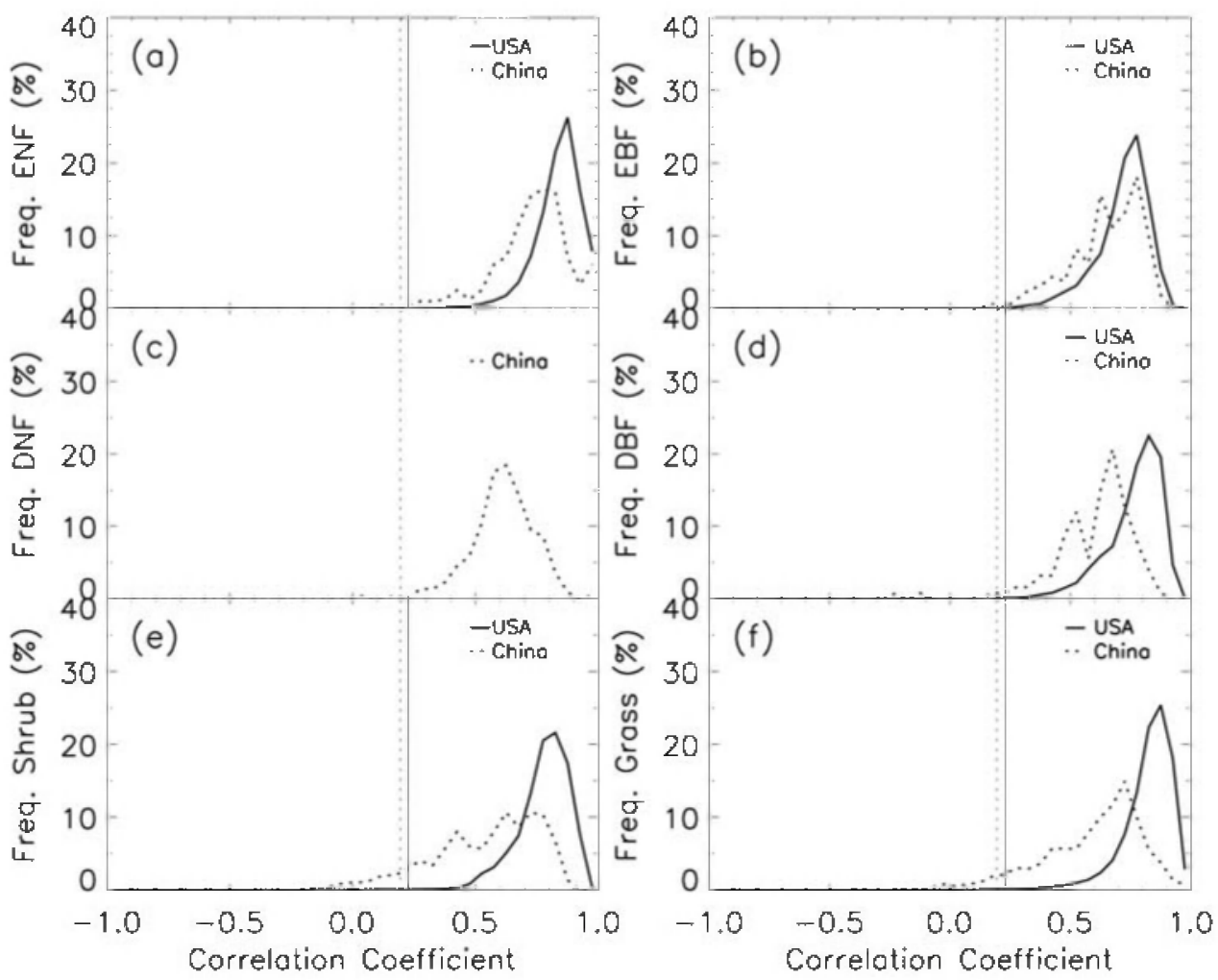

Figure 6. Histogram of annual correlation between Biome-BGC water stress scalars (VPD/SM) and MOD17 water stress scalars (VPD only) for different biome types. Solid lines are for the conterminous United States; dotted lines are for China. The vertical lines stand for the threshold correlation at $\mathrm{p}<0.1$ (dotted lines $r=0.39$ for China and solid lines $r=0.43$ for the conterminous United States).

Qinghai (not shown). The paucity of distributed weather stations in these remote areas likely introduces errors to gridded daily minimum and maximum temperatures as well as daily precipitation, which may consequently cause larger biases in VPD and errors in simulated VPD only, MVPD and MPSI (resulting from errors in the simulated soil water) in Biome-BGC. For other regions where weather stations are denser, the correlation passes at least $p<0.1$ significance test for nearly all pixels (Figure 5), indicating the low correlations might be result of biases in daily meteorology data. The average correlation is $0.61(p<0.006)$ for China and $0.81(p$ $<0.0002$ ) for the conterminous United States. The histogram of the annual correlation for different biomes (Figure 6) indicates that for most of the pixels in a given biome type, the correlation is greater than the threshold correlation at $\mathrm{p}<$ $0.1(r=0.39$ for China; $r=0.43$ for the conterminous United States). On the basis of the spatial correlation maps and the correlation histograms, therefore, the use of VPD alone in MOD17 is adequate to capture the interannual variability of environmental water stress expressed by both VPD and soil moisture in Biome-BGC for both countries, although its performance is better for the conterminous United States than for China.

\subsubsection{Intraannual Variations}

[26] China is a strongly monsoonal country with high temperature and intense precipitation occurring during the growing season. The eastern half of the conterminous United States experiences high growing season temperatures, and precipitation occurs year round [Koeppe and De Long, 1958]. However, a large part of the western
United States has intense precipitation and cold temperatures during winter, and very dry conditions during the growing season [Koeppe and De Long, 1958].

[27] Figure 7 shows the spatial correlation maps between the multiyear averaged monthly VPD/SM and monthly VPD_only during growing season in China and the conterminous United States. Overall, the monthly correlation is not as good as the annual one, and, spatially, it is more complicated. The correlation is positive for most of the conterminous United States and positive over most of China with the exception of the northeast China plain, western China and the Shandong peninsula (Figure 7).

[28] In monsoon-controlled eastern China, the eastern half of the conterminous United States, and the Pacific Northwest of the United States, annual total precipitation is greater than $400 \mathrm{~mm} / \mathrm{yr}$ (Figure 1) and the water stress scalars of both models are large, illustrating that water is not the primary limiting factor for vegetation growth. In addition, the monthly variance of the water stress scalars is small, remaining fairly consistent during the growing season in these areas. As a result, both models have the same seasonality for the water stress, resulting in a large positive correlation.

[29] In the western United States, in the summer, the high VPD resulting from the high temperature creates low values for VPD_only and MVPD. Most of the precipitation occurs in winter, with little precipitation in summer, leading to limited soil water and low variability of monthly precipitation during the growing season. Therefore the dry atmosphere (high VPD caused mainly by high temperature) 

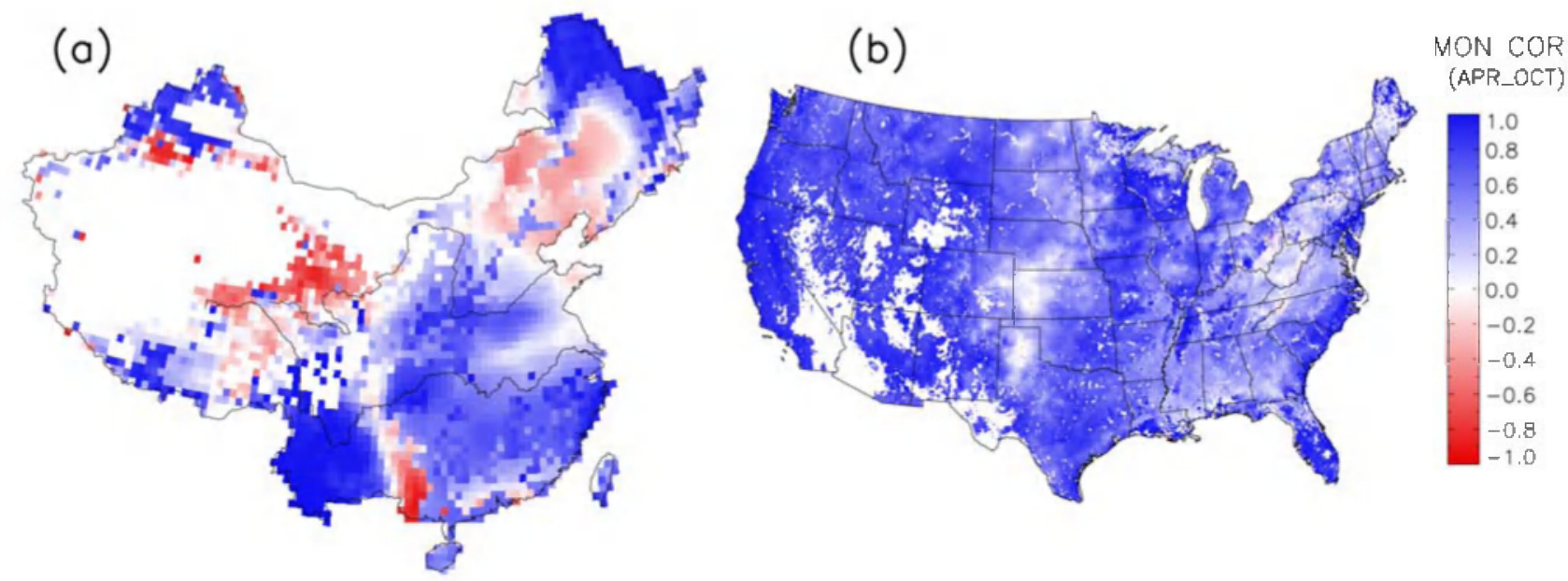

Figure 7. Spatial correlation between monthly Biome-BGC water stress scalars (VPD/SM) and MOD17 water stress scalars (VPD_only) during growing season in (a) China and (b) the conterminous United States. Vegetated regions are shown in color, and the regions in white are either nonvegetated areas, or the areas where the standard deviation of monthly water stress scalars is less than $10^{-5}$.

generally coincides with dry soil conditions (low precipitation), and VPD alone can mimic the entire temporal water stress for these regions, resulting in positive correlation (Figure 7).

[30] In negatively correlated monsoon-controlled areas of China, the climate is dry (Figure 1), and water limitation is strong (Figure 3). Approximately $70 \%$ of the annual precipitation is received in summer when VPD and temperature are high [Northwest Normal University, 1984]. The mismatch between the atmospheric and soil dry/wet periods is responsible for these negative correlation values between two models, suggesting that VPD_only cannot capture the seasonality of the water stress expressed by the atmospheric VPD and the soil water in some of the strongly monsooncontrolled dry areas. The reason for the negative correlation region in southern China (less than $3 \%$ of the country) is that water stress is not the primary limitation to the plant growth. Both VPD/SM and VPD_only are very high and fairly consistent with very low monthly variability.

[31] These results further illustrate that atmospheric VPD_only captures water stress seasonality in regions with relatively little water stress, for example, wet climate or water-stressed regions with dry summer, but it fails to represent the seasonality of water stress in water limited areas with a strong summer monsoon cycle, where soil water effects on vegetation growth should be included. The histograms of seasonal correlation (Figure 8) indicate that, for most pixels of each biome type, the correlation is positive, but there are a number of negatively correlated pixels in China. In addition, VPD_only can capture the seasonality of Biome-BGC water stress better in the conifer forests than in the broadleaf forests and other vegetation areas, because DBF are more sensitive to soil water stress than DNF [Kljun et al., 2004].

\subsection{GPP}

[32] It is fairly easy for most ecosystem models to capture the general seasonality of primary production simply because temperature and solar radiation are used to mimic phenology [White et al., 1997; Leuning et al., 2005]. Comparison of interannual variations in primary production simulated by different ecosystem models, however, can be complex, because different models have different formulations representing ecosystem processes and environmental stresses. More details can be found in section 2.1, 2.2 and the work of Dargaville et al. [2002].

[33] Figure 9 compares the spatial correlation maps of multiyear averaged monthly (Figures 9a and 9b) and annual (Figures 9c and 9d) Biome-BGC simulated GPP with MOD17 estimated GPP. The GPP from the two models agrees better on a monthly basis than at the annual time step. The monthly correlation is positive in most parts of China and the conterminous United States. The annual correlation (Figures 9c and 9d) is usually smaller than the monthly correlation and negative values occur in more places than with the seasonal correlation in both countries (Figures 9a and 9b). Unlike water stress, GPP interannual variability is more difficult to capture than the seasonality, because there are more factors involved in the calculation of GPP. As discussed in section 2, the Biome-BGC and MOD17 algorithms have completely different formulations for calculating GPP. Biome-BGC calculates the potential soil moisture and GPP, and the interannual GPP variability is mainly driven by the variations in climate. The MOD17 algorithm uses climate data and satellite-derived FPAR to estimate GPP, and satellite data can provide some information on the actual vegetation conditions, despite some uncertainties, such as navigational drift, cross calibration of the instrument series and monthly maximum value compositing of FPAR. More research is needed to determine the reasons why GPP differs between the two models.

\section{Conclusion and Discussion}

[34] Water stress is one of the primary limiting factors controlling photosynthesis by terrestrial ecosystems, and its 

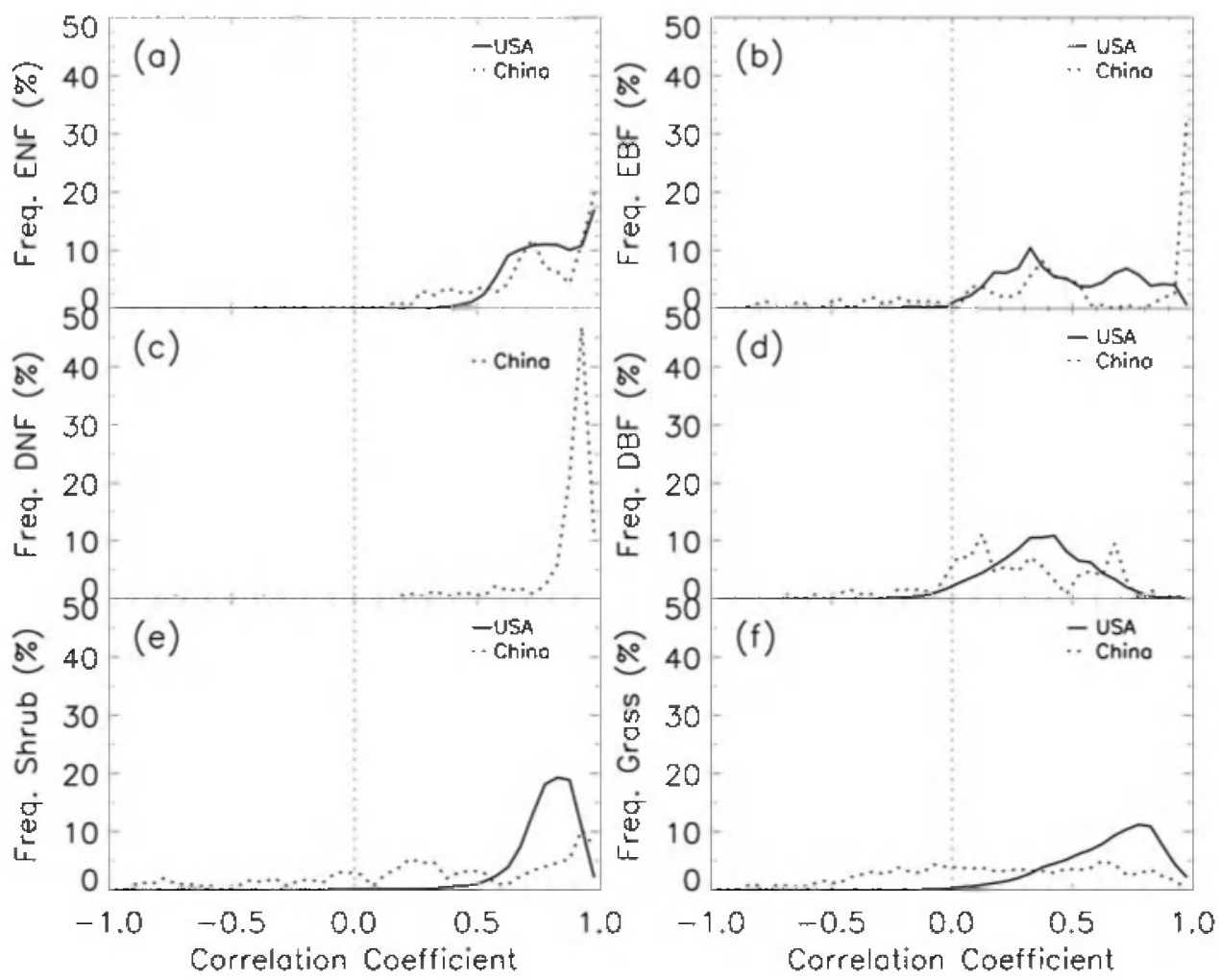

Figure 8. Histogram of monthly correlation between Biome-BGC water stress scalars (VPD/SM) and MOD17 water stress scalars (VPD_only) for different biome types. Solid lines are for the conterminous United States; dotted lines are for China.
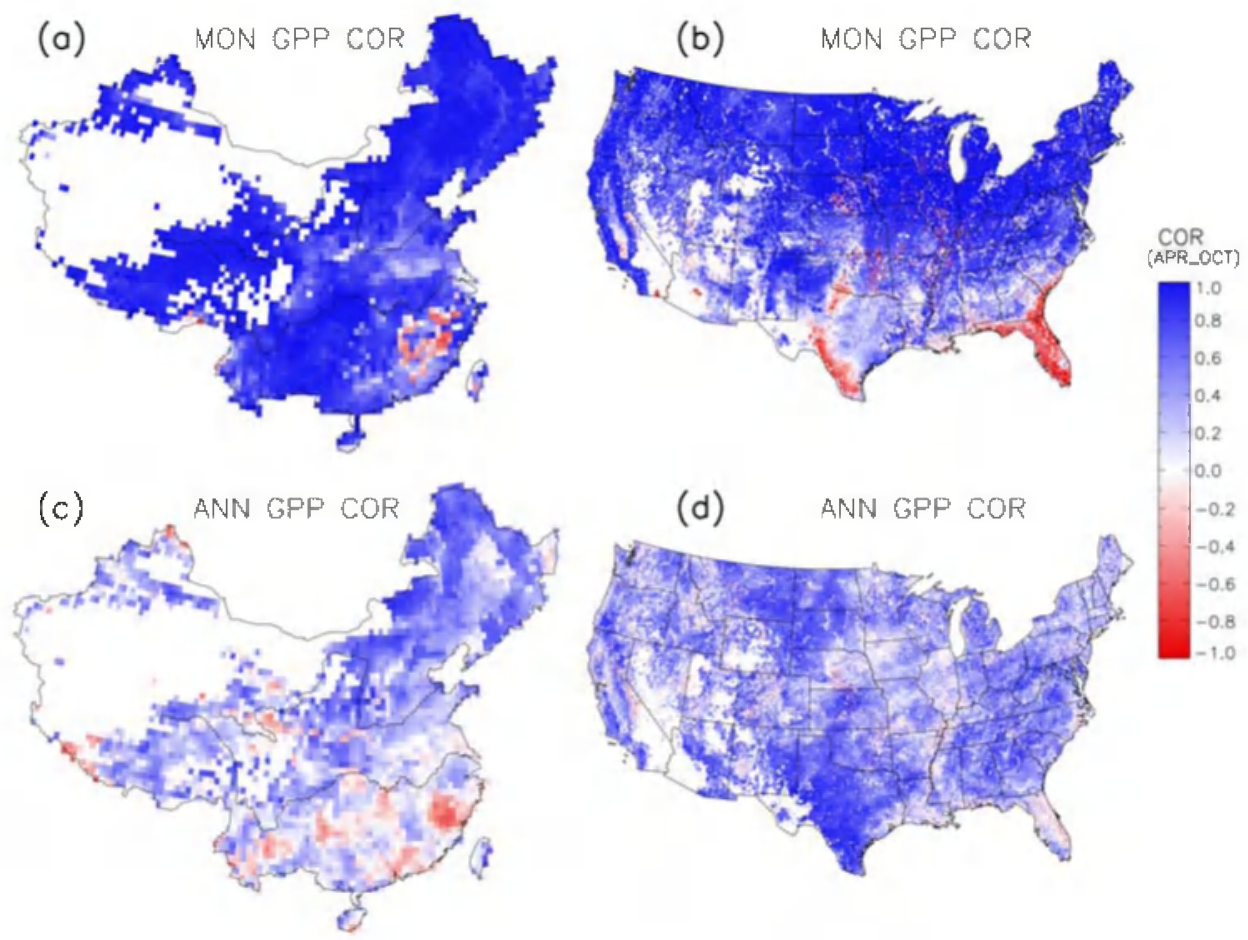

Figure 9. Monthly correlation (a) in China and (b) in the conterminous United States and annual correlation (c) in China and (d) in the conterminous United States between Biome-BGC GPP and MOD17 GPP during growing season. Vegetated regions are shown in color, and the regions in white are either nonvegetated areas, or the areas where the standard deviation of monthly GPP is less than $10^{-5} \mathrm{~g} / \mathrm{m}^{2} /$ month or the standard deviation of annual GPP is less than $10^{-5} \mathrm{~g} / \mathrm{m}^{2} / \mathrm{yr}$. 
accurate representation by ecosystem models is imperative. Ecosystem process models, such as Biome-BGC, generally calculate the water stress as a combination of both atmospheric VPD and soil water limitations. Because of data limitations, however, the global MODIS GPP/NPP algorithm, on the other hand, uses atmospheric VPD alone to express water stress. We have compared the two approaches by comparing the water stress from the MODIS algorithm with similar results from Biome-BGC.

[35] For most of the wetter areas of China and the conterminous United States, water is not strongly limiting, and the VPD variable of the MODIS GPP algorithm reflects the full water stress from the air and soil as determined by Biome-BGC. Using only VPD underestimates the water stress in dry regions where water is severely limiting, such as western China, the northeast China plain, the Shandong peninsula, and the central and western United States. As a result, the MOD17 algorithm overestimates GPP in these areas, suggesting that soil water stress may need to be considered to improve the GPP results. Although VPD alone fails to capture the seasonality of water stress in some areas, it reflects interannual variability in most areas, important for global carbon cycle studies and indicating that the current MOD17 calculations may be adequate for global studies.

[36] The MOD17 water stress (VPD_only) captures the interannual variability of water stress in dry regions in both China and the conterminous United States. It reflects the seasonality of the water stress in the conterminous United States but fails in the monsoonal dry areas of western China, the northeast China plain, and the Shandong peninsula, along with some small areas of southern China, which are wetter and have strong monsoonal control. In general, VPD_only expresses the intraannual and interannual variability of water stress in the conterminous United States much better than that in China. As a result, GPP seasonality is captured better than interannual variability, and this seasonality is captured better in the conterminous United States than in China. The differences between the two countries are driven by climatic differences, such as the strong monsoonal control of China, a climate that has not yet been tested in Biome-BGC. This leads to uncertainty in the estimates of soil and leaf water potential and, thus, the GPP from Biome-BGC, potentially affecting the results of this paper.

[37] While the MOD17 VPD only variable, especially when combined with FPAR, captures water stress for most areas of the two countries, it may be necessary to include soil water stress in extremely dry areas. This has been difficult in the past because of precipitation data set limitations, but current research with microwave remote sensing shows promise for providing accurate estimates of global soil moisture [Jackson, 1993; Njoku and Li, 1999], which can then be used as an input to the MOD17 algorithm, thereby improving GPP estimates. In addition, satellite estimates of ET and PET [Cleugh et al., 2007; Q. Mu et al., Development of a global evapotranspiration algorithm based on MODIS and global meteorology data, submitted to Remote Sensing of Environment, 2007] may also provide methodology to better express water stress without using precipitation or soil moisture.
[38] Acknowledgment. This study is funded by NASA Earth Science Enterprise MODIS contract (NNG04HZ19C) and Interdisciplinary Science Program (NNG04GM39C).

\section{References}

Arora, V. (2002), Modeling vegetation as a dynamic component in soilvegetation-atmosphere transfer schemes and hydrological models, Rev. Geophys., 40(2), 1006, doi:10.1029/2001RG000103.

Asrar, G., M. Fuchs, E. T. Kanemasu, and J. L. Hatfield (1984), Estimating absorbed photosynthetic radiation and leaf area index from spectral reflectance in wheat, Agron. J., 76, 300-306.

Bouchet, R. J. (1963), Évapotranspiration réele et potentielle, signification climatique, in Proceedings of the Berkeley, California, Symposium, Publ. 62 , pp. 134-142, Int. Assoc. of Sci. Hydrol., Gentbrugge, Belgium.

Cao, M. K., S. D. Prince, K. Li, B. Tao, J. Small, and X. Shao (2003), Response of terrestrial carbon uptake to climate interannual variability in China, Global Change Biol., 9, 536-546.

Chabot, B. F., and H. A. Mooney (1985), Physiological Ecology of North American Plant Communities, CRC Press, Boca Raton, Fla.

Churkina, G., et al. (1999), Comparing global models of terrestrial net primary productivity (NPP): The importance of water availability, Global Change Biol., 5, Suppl. 1, 46-55.

Cleugh, H. A., R. Leuning, Q. Mu, and S. W. Running (2007), Regional evapotranspiration estimates from flux tower and MODIS satellite data, Remote Sens. Environ., in press.

Cosby, B. J., and G. M. Hornberger (1984), Identification of photosynthesislight models for aquatic systems, I. Theory and simulations, Ecol. Modell. $23,1-24$.

Cramer, W., et al. (1999), Comparing global models of terrestrial net primary productivity (NPP): Overview and key results, Global Change Biol., 5, Suppl. 1, 1-15.

Cromer, R. N., D. M. Cameron, S. J. Rance, P. A. Ryan, and M. Brown (1993), Response to mutrients in Eucalyptus grandis. 1. Biomass accumulation, For Ecol. Manage, 62, 211-230.

Dang, Q. L., H. A. Margolis, M. R. Coyea, M. Sy, and G. J. Collatz (1997), Regulation of branch-level gas exchange of boreal trees: Roles of shoot water potential and vapour pressure difference, Tree Physiol., 17, 521 535

Dargaville, R. J., et al. (2002), Evaluation of terrestrial carbon cycle models with atmospheric $\mathrm{CO}_{2}$ measurements: Results from transient simulations considering increasing $\mathrm{CO}_{2}$, climate, and land-use effects, Global Biogeochem. Cycles, 16(4), 1092, doi:10.1029/2001GB001426.

De Fries, R. S., M. Hansen, J. R. G. Townshend, and R. Sohlberg (1998) Global land cover classifications at $8 \mathrm{~km}$ spatial resolution: The use of training data derived from Landsat imagery in decision tree classifiers, Int. J. Remote Sens., 19(16), 3141-3168

De Pury, D. G. G., and G. D. Farquhar (1997), Simple scaling of photosynthesis from leaves to canopies without the errors of big-leaf models, Plant Cell Environ., 20, 537-557.

Douglas, O. F., and S. D. Prince (1996), Rainfall and foliar dynamics in tropical southem Africa: Potential impacts of global climate change on savanna vegetation, Clim. Change, 33(1), 69-96.

Field, C. B., J. T. Randerson, and C. M. Malmstrom (1995), Global net primary production: Combining ecology and remote sensing, Remote Sens. Environ., 51, 74-88

Friedl, M. A., et al. (2002), Global land cover mapping from MODIS: Algorithms and early results, Remote Sens. Environ., 83, 287-302.

Goward, S. N., C. J. Tucker, and D. G. Dye (1985), North American vegetation pattems observed with the NOAA-7 Advanced Very High Resolution Radiometer, Vegetatio, 64, 3-14.

Granger, R. J., and D. M. Gray (1989), Evaporation from natural nonsaturated surfaces, J. Hydrol., $111,21-29$.

Heinsch, F. A., et al. (2006), Evaluation of remote sensing based terrestrial productivity from MODIS using tower eddy flux network observations, IEEE Trans. Geosci. Remote Sens., 44, 1908-1925, doi:10.1109/ TGRS.2005.85396

Hou, X. Y. (Ed.) (1980), Chinese Vegetation, Science, Beijing.

Jackson, T. J. (1993), Measuring surface soil moisture using passive microwave remote sensing, Hydrol. Processes, 7, 139-152.

Janowiak, J. E., R. E. Livezey, A. G. C. Kondragunta, and G. J. Huffman (1998), Comparison of reanalysis precipitation with rain gauge and satellite observations, in Proceedings of the First World Climate Research Program International Conference on Reanalyses, WCRP-104, pp. $207-$ 210, World Clim. Res. Program, World Meteorol. Org., Geneva.

Kawamitsu, Y., S. Yoda, and W. Agata (1993), Humidity pretreatmen affects the responses of stomata and $\mathrm{CO}_{2}$ assimilation to vapor pressure difference in C3 and C4 plants, Plant Cell Physiol., 34(1), 113-119.

Kimball, J., S. W. Running, and R. Nemani (1997a), An improved method for estimating surface humidity from daily minimum temperature, Agric For Meteorol, $85,87-98$ 
Kimball, J. S., P. E. Thornton, M. A. White, and S. W. Running (1997b) Simulating forest productivity and surface-atmosphere carbon exchange in the BOREAS study region, Tree Physiol., 17, 589-599.

Kimball, J. S., M. A. White, and S. W. Running (1997c), BIOME-BGC simulations of stand hydrologic processes for BOREAS, J. Geophys. Res., 102(D24), 29,043-29,052.

Kljun, N., T. A. Black, T. J. Griffis, A. G. Barr, D. Gaumont-Guay, K. Morgenstern, J. H. McCaughey, and Z. Nesic (2004), Net carbon exchange of three boreal forests during a drought, paper presented at 26th Conference on Agricultural and Forest Meteorology, Am. Meteorol. Soc., Boston, Mass.

Koeppe, C. E., and G. C. De Long (1958), Weather and Climate, McGrawHill, New York.

Körner, C. (1995), Leaf diffusive conductances in the major vegetation types of the globe, in Ecophysiology of Photosynthesis, edited by E.-D. Schulze and M. M. Caldwell, pp. 463-490, Springer, New York.

Kumar, M., and J. L. Monteith (1982), Remote sensing of crop growth, in Plants and Daylight Spectrum, edited by H. Smith, pp. 133-144, Elsevier, New York.

Landsberg, J. J. (1986), Physiological Ecology of Forest Production, Elsevier, New York.

Landsberg, J. (1999), The Ways Trees Use Water, Water Salinity Issues Agrofor, vol. 5, Rural Ind. Res. Dev. Corp., Kingston, ACT, Australia. (Available at http://www.rirdc.gov.au/reports/AFT/99-37.pdf)

Lange, O. L., W. Beyschlag, and J. D. Tenhunen (1987), Control of leaf carbon assimilation-Input of chemical energy into ecosystem, in Potentials and Limitations of Ecosystem Analysis, edited by E.-D. Schulze and H. Zwölfer, pp. 149-163, Springer, New York

Leuning, R., F. M. Kelliher, D. G. G. Pury, and E.-D. Schulze (1995), Leaf nitrogen, photosynthesis, conductance and transpiration: Scaling from leaves to canopies, Plant Cell Environ., I8, 1183-1200

Leuning, R., H. A. Cleugh, S. J. Zegelin, and D. Hughes (2005), Carbon and water fluxes over a temperate Eucalyptus forest and a tropical wet dry savanna in Australia: Measurements and comparison with MODIS remote sensing estimates, Agric. For Meteorol, 129, 151-173.

Marsden, B. J., V. J. Lieffers, and J. J. Zwiazek (1996), The effect of humidity on photosynthesis and water relations of white spruce seedlings during the early establishment phase, Can. J. For Res., 26, 1015-1021.

Misson, L., J. A. Panek, and A. H. Goldstein (2004), A comparison of three approaches to modeling leaf gas exchange in annually drought-stressed ponderosa pine forests, Tree Physiol., 24, 529-541.

Monteith, J. L. (1972), Solar radiation and productivity in tropical ecosystems, J. Appl. Ecol., 9, 747-766.

Monteith, J. L. (1977), Climate and efficiency of crop production in Britain, Philos. Trans. R. Soc., Ser. B, 281, 277-294.

Morton, F. I. (1983), Operational estimates of areal evapotranspiration and their significance to the science and practice of hydrology, J. Hydrol., 66 , $1-76$.

Myers, B. J., S. Theiveyanathan, N. D. O'Brien, and W. J. Bond (1996), Growth and water use of Eucalyptus grandis and Pinus radiata plantations irrigated with effluent, Tree Physiol., 16, 211-219.

Myneni, R. B., R. R. Nemani, and S. W. Running (1997), Estimation of global leaf area index and absorbed par using radiative transfer models, IEEE Trans. Geosci. Remote Sens., 35, 1380-1393.

Nemani, R. R., S. W. Running, R. A. Pielke, and T. N. Chase (1996), Global vegetation cover changes from coarse resolution satellite data, J. Geophys. Res., 101(D3), 7157-7162.

Nemani, R., M. White, P. Thornton, K. Nishida, S. Reddy, J. Jenkins, and S. Running (2002), Recent trends in hydrologic balance have enhanced the terrestrial carbon sink in the United States, Geophys. Res. Lett. 29(10), 1468, doi:10.1029/2002GL014867.

Nemani, R. R., C. Keeling, H. Hashimoto, W. M. Jolly, S. Piper, C. Tucker, R. Myneni, and S. W. Running (2003), Climate-driven increases in globa terrestrial net primary production from 1982 to 1999 , Science, 300 $1560-1563$

New, M., M. Hulme, and P. Jones (2000), Representing twentieth-century space-time climate variability. Part II: Development of 1901-1996 monthly grids of terrestrial surface climate, J. Clim., 13(13), 2217-2238

Nicholson, S. E., C. J. Tucker, and M. B. Ba (1998), Desertification, drought, and surface vegetation: An example from the West African Sahel, Bull. Am. Meteorol. Soc., 79(5), 815-829.

Njoku, E., and L. Li (1999), Retrieval of land surface parameters using passive microwave measurements at $6-18 \mathrm{GHz}$, IEEE Trans. Geosci. Remote Sens., 37, 79-93.

Northwest Normal University (Eds.) (1984), Chinese Atlas of Physical Geography, 200 pp., China Cartogr. Publ. House, Beijing.

Oren, R., J. S. Sperry, G. G. Katul, D. E. Pataki, B. E. Ewers, N. Phillips, and K. V. R. Schäfer (1999), Survey and synthesis of intra- and interspecific variation in stomatal sensitivity to vapour pressure deficit, Plant Cell Environ, 22, 1515-1526.
Paruelo, J. M., and W. K. Lauenroth (1995), Regional pattern of normalized difference vegetation index in North American shrublands and grasslands, Ecology, 76(6), 1888-1898

Potter, C. S., J. T. Randerson, C. B. Field, P. A. Matson, P. M. Vitousek, H. A. Mooney, and S. A. Klooster (1993), Terrestrial ecosystem production: A process model based on global satellite and surface data, Global Biogeochem. Cycles, 7(4), 811-842.

Prentice, I. C., et al. (2001), The carbon cycle and atmospheric carbon dioxide, in Climate Change 2001: The Scientific Basis-Contribution of Working Group I to the Third Assessment Report of the Intergovernmental Panel on Climate Change, edited by J. T. Houghton et al., pp. 182-237, Cambridge Univ. Press, New York.

Prince, S. D., and S. N. Goward (1995), Global primary production: A remote sensing approach, J. Biogeogr, 22, 815-835.

Rastetter, E. B., A. W. King, B. J. Cosby, G. M. Homberger, R. V. O'Neill and J. E. Hobbie (1992), Aggregating fine-scale ecological knowledge to model coarser-scale attributes of ecosystems, Ecol. Appl., 2(1), 55-70.

Ruimy, A., B. Saugier, and G. Dedieu (1994), Methodology for the estimation of terrestrial net primary production from remotely sensed data, J. Geophys. Res., 99(D3), 5263-5284.

Running, S. W., and E. R. Hunt (1993), Generalization of a forest ecosystem process model for other biomes, Biome-BGC, and an application for global-scale models, in Scaling Physiological Processes: Leaf to Globe, edited by J. R. Ehleringer and C. B. Field, pp. 141-158, Elsevier, New York.

Running, S. W., and J. S. Kimball (2005), Satellite-based analysis of ecological controls for land-surface evaporation resistance, in Encyclopedia of Hydrological Sciences, vol. 3, chap. 104, pp. 1587-1600, edited by M. Anderson, John Wiley, Hoboken, N. J.

Running, S. W., and R. R. Nemani (1988), Relating seasonal patterns of the AVHRR Vegetation Index to simulate photosynthesis and transpiration of forests in different climates, Remote Sens. Environ., 24, 347-367.

Running, S. W., P. E. Thornton, R. R. Nemani, and J. M. Glassy (2000) Global terrestrial gross and net primary productivity from the Earth Observing System, in Methods in Ecosystem Science, edited by O. Sala et al., pp. 44-57, Springer, New York.

Running, S. W., R. R. Nemani, F. A. Heinsch, M. Zhao, M. Reeves, and H. Hashimoto (2004), A continuous satellite-derived measure of global terrestrial primary productivity: Future science and applications, BioScience, 56(6), 547-560

Schultz, P. A., and M. S. Halpert (1995), Global analysis of the relationships among a vegetation index, precipitation, and land surface temperature, Int. J. Remote Sens., 16, 2755-2777.

Sellers, P. J. (1987), Canopy reflectance, photosynthesis and transpiration. II. The role of biophysics in the linearity of their interdependence, Remote Sens. Environ., 21, 143-183.

Sellers, P. J., J. A. Berry, G. J. Collatz, C. B. Field, and F. G. Hall (1992), Canopy reflectance, photosynthesis, and transpiration. III. A reanalysis using improved leaf models and a new canopy integration scheme, Remote Sens. Environ., 42, $187-216$.

Sinclair, T. R., C. E. Murphy, and K. R. Knoerr (1976), Development and evaluation of simplified models for simulating canopy photosynthesis and transpiration, J. Appl. Ecol., 13, 813-829.

Tao, B., et al. (2003), The temporal and spatial patterns of terrestrial net primary productivity in China, J. Geogr. Sci., I3(2), 163-171.

Thornton, P. E., and S. W. Running (1999), An improved algorithm for estimating incident daily solar radiation from measurements of temperature, humidity, and precipitation, Agric. For. Meteorol., 93, 211-228.

Thornton, P. E., S. W. Running, and M. A. White (1997), Generating surfaces of daily meteorology variables over large regions of complex terrain, J. Hydrol., 190, 214-251.

Thornton, P. E., et al. (2002), Modeling and measuring the effects of disturbance history and climate on carbon and water budgets in evergreen needle leaf forests, Agric. For. Meteorol, 113, 185-222.

Turner, D. P., W. D. Ritts, W. B. Cohen, S. T. Gower, M. Zhao, S. W Running, S. C. Wofsy, S. Urbanski, A. L. Dunn, and J. W Munger (2003), Scaling gross primary production (GPP) over boreal and deciduous forest landscapes in support of MODIS GPP product validation, Remote Sens. Environ., 88, 256-270.

Turner, D. P., et al. (2005), Site-level evaluation of satellite-based global terrestrial GPP and NPP monitoring, Global Change Biol, 11, 666-684. Turner, D. P., W. Ritts, M. Zhao, S. Kurc, A. Dunn, S. Wofsy, E. Small, and S. W. Running (2006), Assessing interannual variation in MODIS-based estimates of gross primary production, IEEE Trans. Geosci. Remote Sens., 44, 1899-1907.

Vörösmarty, C. J., C. A. Federer, and A. L. Schloss (1998), Potential evaporation function compared on US watersheds: Possible implication for global-scale water balance and terrestrial ecosystem, J. Hydrol., 207, $147-169$. 
Wang, S., H. Q. Tian, J. Liu, and S. Pan (2003), Pattern and change in soil organic carbon storage in China: 1960s-1980s, Tellus, Ser B, 55, 416-427.

Wang, Y. P., and P. J. Jarvis (1993), Influence of shoot structure on photosynthesis of Sitka spruce (Picea sitchensis), Funct. Ecol., 7, 433-451.

Waring, R., and S. W. Running (1998), Forest Ecosystems: Analysis at Multiple Scales, Elsevier, New York.

White, M. A., P. E. Thornton, and S. W. Running (1997), A continental phenology model for monitoring vegetation responses to interannual climatic variability, Global Biogeochem. Cycles, 11(2), 217-234

White, M. A., P. E. Thornton, S. W. Running, and R. R. Nemani (2000) Parameterization and sensitivity analysis of the BIOME-BGC terrestrial ecosystem model: Net primary production controls, Earth Interact., 4(3), doi: $10.1175 / 1087-3562(2000) 004<0003:$ PASAOT $>2.0 . C O ; 2$.

Wong, S. C., I. R. Cowan, and G. D. Farquhar (1985a), Leaf conductance in relation to rate of $\mathrm{CO}_{2}$ assimilation. I. Influence of nitrogen nutrition, phosphorus nutrition, photon flux density, and ambient partial pressure of $\mathrm{CO}_{2}$ during ontogeny, Plant Physiol., 78, 821-825.

Wong S. C I. R Cowan, and G. D Farquhar (1985b), Leaf conductance in relation to rate of $\mathrm{CO}_{2}$ assimilation. II. Effects of short-term exposure to different photon flux densities, Plant Physiol., 78, 826-829.

Wong, S. C., I. R. Cowan, and G. D. Farquhar (1985c), Leaf conductance in relation to rate of $\mathrm{CO}_{2}$ assimilation. III. Influence of water stress and photoinhibition, Plant Physiol., 78, 830-834.
Zhang, C., H. Tian, J. Liu, S. Wang, M. Liu, S. Pan, and X. Shi (2005) Pools and distributions of soil phosphorus in China, Global Biogeochem Cycles, 19, GB1020, doi:10.1029/2004GB002296.

Zhao, M., C. Fu, X. Yan, and G. Wen (2001), Study on the relationship between different ecosystems and climate in China using NOAA/AVHRR data, Acta Geogr. Sin., 56(3), 287-296.

Zhao, M., F. A. Heinsch, R. R. Nemani, and S. W. Running (2005), Improvements of the MODIS terrestrial gross and net primary production global data set, Remote Sens. Environ., 95, 164-176.

Zhao, M., S. W. Running, and R. R. Nemani (2006), Sensitivity of Moderate Resolution Imaging Spectroradiometer (MODIS) terrestrial primary production to the accuracy of meteorological reanalyses, J. Geophys. Res., 111, G01002, doi:10.1029/2004JG000004.

F. A. Heinsch, Q. Mu, S. W. Running, and M. Zhao, Numerical Terradynamic Simulation Group, Department of Ecosystem and Conservation Sciences, University of Montana, Missoula, MT 59812, USA. (qiaozhen $@$ ntsg.umt.edu) Q.-M. Liu and H. Tian, School of Forestry and Wildlife Sciences, Auburn University, Auburn, AL 36849, USA. 